Boston University School of Law

Scholarly Commons at Boston University School of Law

Faculty Scholarship

1992

Risky Business: Setting Public Health Policy for HIV-infected

Health Care Professionals

George J. Annas

Follow this and additional works at: https://scholarship.law.bu.edu/faculty_scholarship

Part of the Health Law and Policy Commons 


\title{
Risky Business: Setting Public Health Policy for HIV-infected Health Care Professionals
}

\author{
LEONARD H. GLANTZ, \\ WENDY K. MARINER, \\ and GEORGE J. ANNAS
}

Boston University School of Public Health

I

N JULY 1991, ThE UNITED STATES SENATE VOTED 81 to 18 to impose a $\$ 10,000$ fine and a ten-year jail sentence on any HIV-infected physicians who treated patients without disclosing their HIV status. Senator Jesse Helms, the sponsor of the measure, explained his rationale: "Let the punishment fit the crime. . . . I believe in horsewhipping. I feel that strongly about it" (Tolchin 1991). Later, Senator Helms wrote that HIV-infected physicians who practice medicine "should be treated no better than the criminal who guns down a helpless victim on the street" (Helms 1991). In his article he explained that Kimberly Bergalis was the inspiration for his proposal. Ms. Bergalis was not only the inspiration for Senator Helms: when she died of AIDS at the age of 23 in late 1991, she was the first known patient to have been infected with HIV by a health care professional, her dentist, Dr. David Acer (Center for Disease Control 1990). Although it now appears that Dr. Acer infected five of his patients (Centers for Disease Control 1991e), the case of Kimberly Bergalis was the one to capture the public's imagination and has been the driving force behind a movement toward mandatory HIV testing of health care workers. In a letter to Florida health officials in April 1991, which was widely reprinted in the media, she said:

The Milbank Quarterly, Vol. 70, No. 1, 1992

(C) 1992 Milbank Memorial Fund 
Who do I blame? Do I blame myself? I sure don't. I never used IV drugs, never slept with anyone and never had a blood transfusion. I blame every single one of you bastards. Anyone that knew that Dr. Acer was infected ... and stood by not doing a damn thing about it. . . . If laws are not formed to provide protection, then my suffering and death was [sic] in vain. (Kantrowitz 1991, 52)

Although a House-Senate conference committee ultimately rejected the Helms amendment, the Centers for Disease Control (CDC) and the American Medical Association (AMA) both took the position that physicians who engage in "exposure-prone procedures" should know their HIV status and inform their patients of it. When Kimberly Bergalis, shortly before her death, testified before a congressional committee in October 1991 that she "didn't do anything wrong" and urged Congress to enact a law requiring the testing of health care workers for HIV, her 15-second testimony was replayed on all the major networks. One longtime observer of the AIDS epidemic called her testimony "political dynamite"; another termed it "the most dangerous moment in the history of the epidemic" (Berke 1991). Opinion polls show that more than 90 percent of the public believes that all health care workers should inform patients of their HIV status (Kantrowitz 1991). The case of Kimberly Bergalis is seen as proof that the risk of HIV transmission is "real." With virtual unanimity on the issue of informing patients, and with wide support for mandatory HIV screening of health care workers, it is remarkable that both the Helms amendment and less inflammatory proposals have been defeated. In fact, toward the end of 1991, both the CDC and the AMA seemed to be retreating from their previous recommendations to identify exposure-prone procedures and to require HIVinfected physicians who perform them to notify their patients of their HIV status (Leary 1991; Rosenthal 1991b; Williams 1991).

The long dying of Kimberly Bergalis tapped strong emotional currents in the life of Americans and the AIDS epidemic. The reaction by the CDC, the AMA, and some courts has not been exemplary so far. ${ }^{1}$ In this article we will examine that reaction and suggest ways of trans-

\footnotetext{
${ }^{1}$ See e.g., Doe v. Washington University, no. 89-2589-C(4), AIDS Litigation Reporter (Nov. 8, 1991) 7137 (E.D. Mo. 1991); Estate of Behringer v. The Medical Center at Princeton, 249 N.J. Super. 597, 592 A.2d 1251 (Super. Ct. N.J. 1991); In re Application of Milton S. Hershey Medical Center of the Pennsylva-
} 
forming it from a punitive, blame-oriented stance to one that is more likely to protect and promote both the public health and individual rights. The approach we suggest recognizes an important distinction between things that create risk and people who create risk: reducing risks from things is easier to accomplish without denying individuals important freedoms and causing them unwarranted suffering. Things can be made safer by changes in design; if they pose unacceptable risks, they may be eliminated. People must be persuaded or compelled to change their behavior or be removed from contact with people. Yet people may not be deprived of their liberty without good reasons. Thus, policy options to minimize risks that people may pose to others must take into account the human cost of making "risky" human beings safer.

The reaction to the case of Kimberly Bergalis has assumed that health care practitioners can be treated like things, not people. It also suggests that the public is sometimes more frightened by people, especially people with AIDS, than by things. It was recently reported, for example, that a Florida dermatologist infected 213 of 2,331 former patients with hepatitis B virus (HBV) (Tampa Tribune-Times 1991). Three patients died. The number of cases of infection was more than 42 times that occurring among Dr. Acer's patients, but there were no photographs of victims in the newspaper and no front-page stories in weekly magazines. There was no indication that the physician had hepatitis B: rather, the transmission seems to have been caused by unsterile instruments. The resounding silence that met this report may stem from the inability to personalize the source of infection. Stories about sterilization techniques do not make the headlines. Yet it is these infection control techniques that will reduce any risk of HIV transmission in the health care setting. Moreover, they can be used without infringing the rights of health care professionals. $^{2}$

nia State University, Application of Harrisburg Hospital, Appeal of Doe, 595 A.2d 1290 (Super. Ct. of Pa. 1991); Doe v. Attorney General, 941 F.2d 780 (9th Cir. 1991); Leckelt v. Board of Commissioners of Hospital District 1, 909 F.2d 820 (5th Cir. 1990).

${ }^{2}$ We use the term "health care professional" or "practitioner" in this article in lieu of the term "health care worker" because our discussion is restricted to those who may pose a risk to patients by virtue of treating or caring for them directly: physicians, dentists, and nurses. Health care workers, in contrast, are a broader category including individuals who work in the health field but do not treat patients. 


\section{The AIDS Epidemic and the Case of Kimberly Bergalis}

AIDS has afflicted more than 200,000 people in the United States; of these 133,232 have died (Centers for Disease Control 1992). It is well known how the virus is spread, which populations are at highest risk, and that only prevention can stop the dissemination of the virus (Centers for Disease Control 1991c). Among the more than one million people with AIDS or HIV infection, only five have been identified as probably contracting the disease from one dentist. No other case of transmission from health care practitioner to patient is known. Why has this one cluster caused a concern so disproportionate to the numbers?

AIDS is largely a disease of what is deemed to be voluntary behavior: sex and intravenous drug use. As a result, most Americans, particularly white, middle-class Americans, do not feel at risk. Individuals who are heterosexual, relatively monogamous, do not use intravenous drugs, and do not have sex with intravenous drug users can feel confident that AIDS does not threaten their lives. Statistics support their confidence. This sense of personal safety was severely assaulted by the news that a Florida dentist, Dr. David Acer, apparently infected five patients. How these transmissions occurred is still not known and may never be. Was it from a wound through which he bled into a patient's wound? Was it the result of his apparently poor infection control procedures? Or was it the intentional act of a deranged or spiteful person? Whatever the answer, the general public feels newly vulnerable. If Kimberly Bergalis, an attractive, young, white woman who did not engage in other risky behaviors, can suffer and die from this horrible disease, then no one can feel safe. Perhaps as important, Ms. Bergalis contracted the disease from a dentist, a health care professional, whose role is to enhance health, not to cause infection with a deadly virus.

This single case of transmission has diverted our attention from the work that is required to slow the epidemic. Unlike programs designed to convince intravenous drug users to use clean needles or at-risk individuals to use condoms, the issue of HIV-positive health care professionals is largely irrelevant to the public health goal of controlling the AIDS epidemic because these individuals do not spread it. If every HIV-positive health care worker were excluded from practice, it would have virtually no impact on the epidemic. 
Nevertheless, the public debate over HIV-infected health care professionals offers an opportunity to consider how to protect the rights of HIV-positive practitioners and how rationally to assess risks to others. The goal of public health should be to ascertain risks to a population, put these risks in perspective, and try to identify reasonable actions that will reduce risks. When a risk appears very frightening, public health experts must provide accurate information and suggest appropriate action without inciting public panic or unduly restricting individual freedom. Of course, reasonable measures should be taken by hospitals and health care workers to reduce the risk of HIV transmission. The question is, What steps are reasonable in accomplishing this goal?

Discrimination against health care professionals is not a reasonable or necessary means of combatting the AIDS epidemic. Health care professionals, particularly surgeons, are not typically viewed as members of an oppressed class in need of protection. However, once they are infected, their HIV-positive status quickly overshadows their occupational status, and leaves them as vulnerable as any other person with HIV to discriminatory treatment by their employers. As such, they need and deserve the protection of antidiscrimination law and policy.

\section{The Response of the CDC}

Even prior to the Acer case, the Centers for Disease Control had adopted policies regarding HIV-positive health care workers (Centers for Disease Control 1985, 1986, 1987). Although the CDC's response had been cautious and somewhat equivocal (Barnes et al. 1990), it had always emphasized infection control measures. The 1985 recommendations stressed that infected workers who performed noninvasive procedures presented no risk of harm to others, offered no opinion on the "employability of infected workers performing invasive procedures," specifically deferred the question of testing practitioners who perform invasive procedures, and recommended that infected health care workers undergo an individual review by their personal physician and the employee health services to determine ways to minimize their own risk of acquiring infectious diseases from patients (Centers for Disease Control 1985).

In 1986 the CDC stated that mandatory HIV screening of health care practitioners who performed invasive procedures was not necessary because testing would not further reduce the "negligible risks of transmission" if 
universal precautions were used (Centers for Disease Control 1986). The CDC determined these risks to be so negligible that infected health care practitioners could safely continue to perform invasive procedures. The 1987 guidelines have been characterized as "reversing course" (Barnes et al. 1990). Rather than eschewing mandatory testing, the CDC said it could not assess the "utility of routine testing" and pointed out that transmission from infected health care practitioners to patients "remains a possibility" (Centers for Disease Control 1987). The 1987 guidelines also called for individual review of all infected workers, not just those who perform invasive procedures, so the employer institution could determine if the health care worker "can adequately and safely be allowed to perform patient-care duties. . ." (Barnes 1990, 314). Still, in the absence of any well-publicized case of practitioner-to-patient transmission, none of these earlier recommendations led to screening all health care practitioners for HIV infection.

The CDC's "Recommendations for Preventing Transmission of Human Immunodeficiency Virus and Hepatitis B Virus to Patients During Exposure-Prone Invasive Procedures" were issued on July 12, 1991, after Dr. Acer and Kimberly Bergalis became household names (Centers for Disease Control 1991b). In the background section, the CDC noted that since the early 1970s there have been published reports of 20 clusters of hepatitis $\mathrm{B}$ virus (HBV) involving transmission from practitioners with $\mathrm{HBV}$ to more than 300 patients. In 12 of the clusters the practitioner did not wear gloves. Most of these clusters "occurred before awareness increased of the risks of blood-borne pathogens in health care settings," and the use of universal precautions (Centers for Disease Control 1991b). The report then stated: "The limited number of reports of HBV transmission from [health care workers] to patients in recent years may reflect the adoption of universal precautions and increased use of HBV vaccine."

The CDC estimated that the risk of transmitting HIV is one hundredth of the risk of transmitting $\mathrm{HBV}$ and that there was one reported HIV transmission cluster involving one dentist and five patients; moreover, four studies involving three HIV-infected surgeons and one HIVinfected dental student found no transmissions (Centers for Disease Control 1991b). Nevertheless, the CDC assumed that certain procedures are "exposure-prone," particularly those that involve "digital palpation of a needle tip in a body cavity or the simultaneous presence of the health care worker's finger and a needle or other sharp instrument or object in a poorly visualized or highly confined anatomic site." 
On the basis of this experience with HBV transmission and its assumption about exposure-prone procedures, in July 1991 the CDC recommended:

1. Adherence to universal precautions and other infection control sterilization procedures.

2. No restrictions on the practice of health care workers infected with HIV or HBV who perform invasive procedures that are not "exposure-prone" as long as they use universal precautions and practice recommended surgical or dental techniques.

3. Exposure-prone procedures should be identified by medical/surgi$\mathrm{cal} /$ dental organizations and institutions.

4. Health care workers who perform exposure-prone procedures "should know" their HIV antibody status and their HBV status.

5. Health care workers "who are infected with HIV or HBV (and are $\mathrm{HBeAg}$ positive) should not perform exposure-prone procedures unless they have sought counsel from an expert review panel and been advised under what circumstances, if any, they may continue to perform these procedures. Such circumstances would include notifying prospective patient of the health care workers' seropositivity before they undergo exposure-prone invasive procedures."

6. There should not be mandatory testing of health care workers (Centers for Disease Control 1991b).

The CDC also stated that health care workers whose practices are modified because of their HIV or HBV status should be provided opportunities for appropriate patient care activities, career counseling, and job retraining.

The recommendations are internally inconsistent. They state that health care workers should know whether they are infected with HIV or HBV. The only way to enforce such a recommendation would be by testing, yet mandatory testing was specifically rejected. In support of its position against mandatory testing, the $\mathrm{CDC}$ argued that the current assessment of the risk of transmission does not support the "diversion of resources that would be required to implement such a mandatory testing program" (Centers for Disease Control 1991b). However, if all health care practitioners who perform exposure-prone procedures should know their HIV antibody status, the resources required to comply with this recommendation would be no different from the resources required for 
mandatory testing. Furthermore, if the CDC believed health care practitioners who perform invasive procedures were dangerous enough to be prohibited from performing such procedures, then, to be consistent, the CDC should at least have encouraged institutions to try to locate these workers. The expert review panel's function under these recommendations is also unclear. If an infected health care practitioner could not perform invasive procedures, and these procedures were defined or listed as the CDC planned, what role could such a review panel perform?

Finally, the patient notification provision was not an infection control measure. We are not aware of another infection control measure that may be overridden by patient consent. The CDC did not state that health care practitioners could decide to forego the use of universal precautions or the sterilization of their instruments with the consent of their patients. If infected practitioners are too dangerous to perform invasive procedures, and are thereby a menace to public health, notifying patients will not remove this danger. It would be an odd public health measure that substituted consent to risk for risk prevention, especially in the context of an epidemic. Of course, if no patient would consent, then the recommendation that patients be notified of a practitioner's seropositivity would produce the same result as a recommendation that such practitioners cease practice.

What might have led to such incoherent recommendations? One possibility may have been the political climate in Congress. While the CDC deliberated over its recommendations, Congress had before it bills that proposed mandatory testing of health care practitioners and criminal sanctions for infected practitioners who performed invasive procedures. Senator Helms's bill was introduced in January 1991 and a revised bill was voted on in July 1991 (U.S. Congress 1991c). The mandatory testing bill was introduced by Representative Dannemeyer only a few weeks before the recommendations were issued (U.S. Congress 1991a). Even if the CDC believed that mandatory testing and exclusion were unwarranted, it may have felt pressured to take a stand that would appear to provide increased public protection in order to forestall more radical congressional action. In this sense the CDC's July 12, 1991, recommendations can be viewed as a political compromise. They were much more stringent than their prior recommendations, yet they were based on little or no additional information on the history of HIV and HBV transmission, needlestick injuries, or related data. The CDC, in fact, prefaced its specific recommendations by stating that the risk of $\mathrm{HBV}$ 
transmission from health care worker to patient is "small" and the risk of transmitting HIV is "even smaller" (Centers for Disease Control 1991b). Because the risk of HBV transmission has always been small and is declining, and the risk of HIV transmission is one hundredth that of HBV transmission, the only reason for issuing new recommendations appears to have been to make a public response to the Acer case.

\section{The AMA's Reaction}

The American Medical Association (AMA) issued guidelines in 1988 stating that "if a risk of transmission" of an infectious disease exists from a particular activity, the physician "should not engage in the activity" (Barnes et al. 1990). The 1988 guidelines also noted that disclosure to patients was not sufficient (American Medical Association 1988). On January 17, 1991, immediately after the CDC confirmed the Acer case (Centers for Disease Control 1991e), which had been first reported six months earlier, the AMA issued a statement on HIV-infected physicians (American Medical Association 1991). The statement began, "Physicians who are HIV positive have an ethical obligation not to engage in any professional activity which has an identifiable risk of transmission of the infection to the patient" [emphasis added] (American Medical Association 1991). The statement then explained that, although there has never been a case of transmission of HIV from a physician to a patient, the Acer case caused some uncertainty about the risk of transmission; where there was such uncertainty the medical profession "should err on the side of protecting patients." The AMA concluded that physicians must either abstain from performing invasive procedures that pose an "identifiable risk of transmission," or "disclose their seropositive status prior to performing a procedure and proceed only if there is informed consent."

The AMA statement sets forth a remarkable notion of risk-one it had never before used to guide the practice of medicine. If the AMA applied this strict "ethical" standard to all physicians, not just HIVinfected physicians, it would make the practice of medicine impossible. In its 1988 statement the AMA had used the term "a risk" of transmission. In 1991 it used the term "identifiable risk." Neither the term "a risk" nor "identifiable risk" provides any leeway. Airplanes falling out of the sky and crushing people in their homes, being hit by lightning, 
and death from anesthesia are all risks and identifiable risks. It is remarkable that the AMA would assert that physicians may not subject people to any risks. If this were so, it would certainly be the end of the practice of surgery, of prescribing drugs, and of taking $\mathrm{X}$ rays. It is notable that the statement by the AMA, a group not known for strong stands on patients' rights, indicates a belief that physicians have an ethical obligation to inform patients of identifiable risks, a standard much more expansive than the most patient-centered court or legislature would dream of imposing (Annas, Glantz, and Katz 1977; Faden and Beauchamp 1986).

Dr. Nancy Dickey, an AMA trustee, has said that the risk of HIV transmission is very low, but "real" (Barnes 1990). This seems odd because there has been no case of a physician transmitting HIV to a patient. Indeed, "lookback" studies have tested former patients of physicians who had AIDS without finding a single instance of physician-to-patient HIV transmission (Armstrong, Miner, and Wolfe 1987; Danila et al. 1991; Mishu et al. 1990). Dr. Dickey also has argued that the AMA policy is derived from the physician's obligation to "do no harm." But her reliance on this doctrine is surely misplaced. There is a distinction between "do no harm" and "do nothing that risks harm." If physicians could not risk harm, no drug or surgery could be used. When it comes to HIV the AMA has been unable to distinguish between the risk of harm and harm itself.

According to the logic of the AMA's statement, a one in a billion risk, a one in 100,000 risk, and a one in two risk should all be treated equally because each risk is "identifiable." Because the AMA cannot possibly believe this, it must believe that the risk of AIDS should be treated differently from all other types of risks. For example, a recent study of the incidence of malpractice in New York state found that a patient in a New York hospital has about a 1 percent chance of being injured as a result of malpractice (Brennan et al. 1991). An estimated 100,000 additional patients were injured as a result of adverse events not caused by negligence in 1984 . About 13,000 patients a year die from adverse events, with 7,000 attributable to negligent care. This means that approximately 20 patients per day die from negligent care in one state alone. However, there has been no response from the AMA calling for measures to reduce these risks, urging physicians to avoid sending patients to New York hospitals, or requiring physicians who have been guilty of malpractice to so notify their patients.

Why did the AMA so readily abandon its HIV-infected colleagues? It 
certainly took no similar action in the 1970s when HBV clusters were being discovered. The AMA's reaction may have been stimulated by several considerations. First, there may be a genuine concern for patient safety, although it is unclear why the AMA would choose this minuscule risk on which to take a stand if patient safety were its primary concern. Second, only a few physicians will be affected by the policy, and in return the AMA could represent to the public that it is protecting patients, even at the cost of restricting the practice of physicians. With doctors and patients increasingly viewing each other as threats rather than as partners in a therapeutic relationship, there is much to be said for this goal, however misguided its means of attainment. Third, there is no reason to believe that physicians want to be treated by HIV-infected physicians any more than the general population. Finally, the AMA policy may simply be an indication of the power of the AIDS stigma. HIVinfected doctors are no longer viewed primarily as doctors, even by their own colleagues, but are largely placed in the role of agents of harm.

In any event, if the CDC's and AMA's goals were to calm the American public, their methods backfired. By concluding that some HIVinfected physicians were simply too dangerous to practice medicine, they only inflamed public fears. Both policies fed the fear of large numbers of individuals who do not engage in at-risk behaviors that some doctors could kill them. Nice distinctions between invasive and noninvasive procedures may be lost on the public. Physicians, regardless of speciality, cannot feel that their careers are safe if they are HIV infected.

\section{New Recommendations, Similar Problems}

In late 1991, both the CDC and the AMA reconsidered their policies on HIV-infected health care workers, presumably in response to the negative reaction of medical, public health, and community groups (American College of Obstetricians and Gynecologists 1991; Hilts 1991; Leary 1991; New York State Department of Health 1991; Rogers and Osborne 1991; Rosenthal 1991a,b; Scott 1991). The CDC drafted new recommendations that abandoned the creation of a list of exposure-prone procedures. Although the final version of new recommendations was not available by the end of the year, preliminary drafts may indicate a new approach. In one draft, the CDC concluded that the determination of whether a particular invasive procedure is exposure prone must be made 
on an individual basis, considering the individual's technique, skill, and medical condition as well as the procedure itself (Centers for Disease Control 1991a). This recognizes, correctly we think, that if any risk of transmission exists, it would be the result, not of the mere fact that a health care professional was infected with HIV, but of the practitioner's lack of skill or technique. The risk is skill specific, not procedure specific.

The draft recommendations indicate that HIV- (and HBV-) infected health care practitioners who perform surgical and obstetric procedures (involving surgical entry into tissues, cavities, or organs) or procedures involving cutting or removal of oral or perioral tissues should seek advice from an expert review panel to determine which procedures should and should not be performed. The review panel is to base its decision on three factors:

1. whether the practitioner performs procedures that "could result" in injury from the practitioner's blood contaminating the patient's body cavity or tissues

2. the practitioner's techniques, skill, and experience, and compliance with infection control practices

3. any physical or mental impairment that may interfere with the practitioner's ability to practice properly

The potential utility of such recommendations, if they are adopted, is unclear. If the $\mathrm{CDC}$ and most medical specialty groups cannot identify exposure-prone procedures that could result in transmission, it is unlikely that a local "expert" panel can do so, as the first factor would require. Without identifying specific procedures, any invasive procedure might pose a theoretical risk under the right circumstances, so all such procedures could be considered relevant. Different local panels may also create different lists, and there is no reason to believe that they will be consistent from place to place. Local hospitals tend to be more protective of institutional interests than of individual rights. Thus, the use of local panels invites arbitrary decisions. A physician could move from town to town and be subject to different rules in each place.

Where the expert panel is uncertain about whether procedures may pose a "small risk" - which is likely to be often - the draft recommendations permit advising the practitioner to perform certain procedures only with the patient's consent. This perpetuates the misconception that there is a right to know the HIV status of a health care professional. 
Moreover, all health care practitioners, not just those who are HIV or HBV infected, should be (and are already) subject to the second and third requirements because these concern the person's ability to practice competently. Unfortunately the draft recommendations imply that these requirements apply only to health care workers with HIV or HBV infection. However, a hospital or other employer does not need to know a practitioner's HIV or HBV status to ensure that he or she has adequate skills and abilities for practice. Health care practitioners who cannot meet these requirements should be retrained or suspended from practice until they meet professional standards, regardless of their HIV or HBV status.

Finally, this draft of the new recommendations states that current assessments of the risk of transmission do not justify mandatory testing, yet they continue to recommend that health care workers who perform certain invasive procedures should know their antibody status. Thus, the basis for the very mandatory testing that the CDC finds unjustified remains in its draft revised recommendations.

At the same time, the draft recommendations offer a beneficial new addition: they list procedures that are "not invasive," thereby clarifying which procedures do not present a risk of transmission and helping to assuage the unnecessary fears of patients. This should also remove an excuse for hospitals and courts who misapprehend the risk of transmission summarily to fire health care practitioners who perform these noninvasive procedures without posing any risk of transmission.

\section{Risk Perception}

These reactions to the case of Dr. Acer and Ms. Bergalis seem to be based on the assumption that personal fears and perceptions of risk are sufficient to dictate public policy, regardless of the consequences. Both the general public and the health professions are increasingly incapable of assessing risks and putting them in perspective in contemporary America. This is because risk perception has come to be based, not on probabilities, but rather on excessive personal perceptions of vulnerability, political considerations, and changing societal expectations (Barsky 1988). The concept of "acceptable risk" (Fischoff 1981) is disappearing and being replaced by a "no-risk" ethic-indeed the AMA policy (and, 
to a large degree, the CDC policy) tries to promise a risk-free world. It is no surprise that the public prefers no risk. What is new is the willingness of the experts to embrace the same notion in the case of HIV transmission.

Ordinarily, the public perceives particular risks quite differently than experts do. Experts focus on the probability and magnitude of a hazardous occurrence, whereas the public often ignores quantitative assessments and worries about the nature of a potential hazard, without regard to the likelihood that it will happen (Slovic 1987). For example, the public may greatly fear a minuscule chance of dying in a nuclear reactor accident, while accepting a much larger and more immediate chance of dying in a motor vehicle accident. One reason for this is the newness of the threat. When it comes to risks, familiarity often breeds acceptance. A new threat stands out distinctly from the background, and is rarely compared with familiar existing risks. Increasingly, smaller and smaller risks have this bas-relief effect. As science and public health all but eradicated the historically significant killers - by sanitation, clean water, and pure food-lesser risks moved to the foreground.

Public reaction to new risks is also affected by the "ease with which adverse consequences can be imagined" (Lichenstein et al. 1978; Slovic 1991, 303; Tversky and Kahneman 1973). Science fiction may have endowed the public with a particularly rich imagination for disasters caused by exotic new technology and diseases. Similarly, public reaction to a given cause of death is affected by "psychic proximity" (Rescher 1987). Our ability to imagine ourselves in the place of victims tends to shape our opinion of whether or not the risk is tolerable.

Risks also tend to be tolerated in direct proportion to the degree to which they are voluntarily accepted by their victims. When benefits are apparent and immediate, risks are also more easily accepted than when benefits accrue over many years and are spread over a large population or are enjoyed by those who did not take the initial risk (Slovic 1987, 1991). Risks of many medications are accepted, whereas having a hazardous waste facility next door is not.

Finally, there is what might be called the "horror quotient" of danger. The more horrible the type of death, and the more imaginable that horror, the more intolerable it becomes (Rescher 1987). If people think of death at all, they are more likely to consider how they do not want to die than how they probably will die. 
Kimberly Bergalis's death from AIDS presumably acquired from her dentist combines all the characteristics that influence individuals' perception of their own risk and amplify the resulting fear. Most heterosexual, non-IV drug user Americans do not see themselves as at risk for HIV infection. The infection of Kimberly Bergalis represented a new threat. The nature of AIDS, as played out in public by her dying, was especially horrible. The public naturally concentrated on the real harm to Ms. Bergalis, rather than on the probability of that harm occurring. Also, because it was seen as a new harm, it regained immediate attention. "Old" background harms from physicians, such as iatrogenic diseases, nosocomial infections, or negligently caused injuries, were ignored because they were familiar and had already been accepted. It was also very easy for middle-class Americans to identify with Ms. Bergalis and to imagine her fate being theirs. Finally, because her dentist did not tell her of his HIV status, she was exposed to risk involuntarily, and such risks are even less tolerated.

Theories of risk perception help explain the public reaction to the Acer/Bergalis case, but they do not tell us anything about whether this reaction is justified. In particular, public fear of any given danger alone, however real, has never been sufficient by itself to require that steps be taken to eliminate the danger entirely. Social policy must take into account more than individual fear. It must weigh the possible benefits and costs of a potentially dangerous social activity against the benefits and costs that would result from avoiding the activity. In particular, responsible social policy requires distinguishing between regulating things perceived as dangerous, such as chemicals with no rights, and regulating people perceived as dangerous, who do have rights. The level of tolerable risk may be higher when people, rather than things, are the source of risk because the burdens on people, including the loss of their rights, required to reduce a risk may be less tolerable than living with slightly more risk.

Social decisions to accept or prevent particular risks seem to classify risks into two general categories: (1) socially impermissible risks that no one should be allowed to take or impose on others include such activities as landing aircraft on a residential street and shooting guns in the city; and (2) socially acceptable risks that are tolerated by society. Socially acceptable risks may be further divided into two classes: (a) optional risks that people may choose to take or avoid, and (b) accepted 
risks that people may be compelled to take or have imposed on them because the compensating benefits or the costs of avoiding the risk are too great. Optional risks include activities and products with potential dangers, such as smoking cigarettes, drinking alcohol, taking prescription drugs, working as a high-rise window washer, playing football, and undergoing surgery. Society is willing to permit people voluntarily to take their chances with such things, but does not require people to indulge. Accepted risks are those that at least some people may not avoid, regardless of their preferences, without leaving the society. Minimum levels of pollution and automobile use have been deemed a tolerable risk of living in society. Perhaps the best example of accepted risks are childhood immunization programs, which require children to be immunized against infectious diseases. A few children will suffer serious adverse reactions to a vaccine so that society at large can be protected from infectious diseases. The determinative factors in classifying risks into these three categories are the nature of the harm, the probability it will occur, the accompanying benefits, and the costs, both economic and human, of avoiding them.

Social policy decision making on risks is the process of evaluating and weighing these factors to classify risks as socially impermissible, optional, or accepted. Exaggerated fears sometimes drive policy making. The question is not, however, whether people are afraid of getting HIV or AIDS from health care professionals; it is whether that fear justifies a policy of excluding health care professionals from taking care of patients. To answer this question, it is necessary to analyze critically the degree of risk posed by HIV-infected practitioners, the benefits of permitting them to continue to practice, and the costs of excluding them from practice. When, as here, however, people are the source of risk, the analysis of policy options requires an additional consideration. Although the approach is similar to analyzing the reduction of risks caused by things, it must measure the costs in human terms. When people are the source of risk, one of the costs of risk reduction is human rights.

Much of the post-Bergalis political debate has assumed that HIVinfected health care practitioners offer little or no benefit to patients and that the risk they pose could be avoided at no cost (see the article by Daniels in this issue). The risk has been assumed to be unacceptably high, without characterizing it more specifically than "a risk" or "real." For example, the proposed Kimberly Bergalis Patient and Health Provider Protection Act of 1991 would have prohibited anyone with "HIV 
disease" from performing medical and dental procedures that would pose "a risk" of transmission to a patient (U.S. Congress 1991a). This bill, which was superseded by Public Law 102-141 requiring states to issue their own guidelines, characterized any risk of HIV transmission from health care practitioner to patient as socially impermissible. ${ }^{3}$ Another provision of the same bill, however, would have permitted health care professionals to perform such prohibited procedures if they informed the patient that they had HIV disease and obtained the patient's written consent. This inconsistent provision characterized the risk as optional.

Ironically, many supporters of this and similar bills are self-described political conservatives. They ordinarily subscribe to the idea that the public is too risk averse and should accept more, or at least existing, risks as the reasonable cost of economic development and industrial progress (Wildavsky and Dake 1990; Zeckhauser and Viscusi 1990). Political liberals, on the other hand, have often advocated reducing even small risks, to the environment and ecology, for example, but they are reluctant to infringe on individual rights (Wildavsky and Dake 1990). In this case, the economic benefits of keeping HIV-infected health care professionals in practice are not well understood, whereas the major visible costs of excluding them accrue to the practitioners themselves. Thus, conservatives and liberals have reversed positions on the issue of HIVinfected health care practitioners. This is because the goal of protecting patients from exposure to HIV infection is being sought not by merely regulating things, but at the expense of the liberty of health care practitioners.

The general goal of increasing patient safety is unquestionably worthwhile and important. The issue, in this instance, is whether this goal is attainable without abridging the rights of practitioners.

\section{Risks and Rights}

For years persons with disabilities were excluded from schools and workplaces. It was often, and still is, argued that persons with disabilities pose a danger to others. A deaf person might not be able to follow verbal instructions in an emergency. A wheelchair user might block exit

\footnotetext{
${ }^{3}$ P.L.102-141. Approved October 28, 1991. Treasury, Postal Service and General Government Appropriations Act, 1992. 102d Congress (1991).
} 
routes in a fire. Recently the executive director of the President's Committee on the Employment of People with Disabilities was denied transportation by a commuter airline because he used a wheelchair. Officials of the airline explained, "If you can't walk up and down the stairs you are a danger to yourself and a safety hazard" (Holmes 1991). Rick Douglas, the person denied boarding, said, "I'm still stunned." And well he should be. There are no reports, as far as we can find, of wheelchair-related airline deaths. Of all the things that kill people in air crashes, the presence of a wheelchair, or a person who uses a wheelchair, would appear to be an insignificant causal factor.

The assumption that Mr. Douglas presents a danger to others is based on a series of "what ifs." What if there is a crash, and what if everyone does not die instantly, and what if all the exits are blocked except for the one with the wheelchair in its way. The presence of a person who uses a wheelchair on a plane may, in fact, increase risks to others. Indeed, that risk is probably identifiable. However, the social policy question is whether the perceived risk is great enough to exclude wheelchair users from engaging in activities that require air travel. The answer is no.

When the federal Rehabilitation Act of 1973 was passed, and, more recently, when the Americans with Disabilities Act (ADA) was enacted, the risk presented by people with disabling conditions was balanced against the harm done to disabled persons, and the larger society, by excluding these persons from activities the rest of society enjoys and values. The acts embody the social policy decision that some risks should be tolerated to achieve the larger goal of social justice for those who could participate in society if, instead of creating artificial barriers, it lowered some of the existing barriers. The rules of the "what if" game were changed.

James Strathie, for example, was issued a license to drive a school bus after successfully completing a training course and passing the bus driver's licensing test required by the Pennsylvania Department of Transportation. After safely working as a school bus driver for one day, he was notified by the department that his license was suspended indefinitely because he wore a hearing aid. The department's regulation required school-bus drivers to have hearing capacity Mr. Strathie could not meet without his hearing aid. The department argued that its licensing program was designed "to ensure the highest level of safety," and viewed its responsibility as eliminating "as many potential safety 
risks as it can." The department argued a series of what ifs: what if the hearing aid becomes dislodged, or the battery suddenly wears out, or the hearing aid simply breaks. All of these matters can be addressed by inspection of hearing aids or regular battery replacement or having an extra on hand, as Strathie volunteered to do. Of course, a driver whose hearing aid is dislodged presents much less of a risk than a driver whose eyeglasses become dislodged. The federal court of appeals decided that the district court's ruling, which had accepted the department's arguments and permitted his exclusion from the workplace, was wrong. ${ }^{4}$

Drivers who wear hearing aids or eyeglasses may well present risks to others on the road that are not presented by drivers who do not require such aids. However, such identifiable risks are not sufficient to prohibit these individuals from engaging in the activities, not only because the risks are remote and minimal, but also because the negative impact on the life of the excluded individual is great.

The fact that people have an exaggerated fear of a particular risk is not enough to prohibit an otherwise qualified person from engaging in common activities. In 1985, a group of frightened parents learned that an HIV-infected seven-year-old child was to attend a public school. These parents sued the New York City Board of Education either to prohibit this child's admission or to require the board to identify the child. ${ }^{5}$ To its credit, the board defended this child's right to receive a public education free of harassment. In 1985, AIDS was still a relatively new phenomenon, particularly to this Queens neighborhood. The parents presented a series of what-if scenarios: what if the infected child bites another child, or what if there is a fight in the school yard and the infected child bleeds on another child with an open wound? All the public health authorities testified that risk of transmission from child to child was highly unlikely. The terms used included "highly, highly improbable," "highly unlikely," "extremely highly improbable" and "practically nonexistent." What parents wanted, however, was a guarantee of absolute safety, something that scientists do not provide. The parents' position was, Why take any risk? Who wants to be the first victim?

The court rejected a zero risk standard, saying that some "minimal theoretical risk" is not enough to exclude children from school. ${ }^{6}$ The

\footnotetext{
${ }_{4}^{4}$ Strathie v. Department of Transportation, 716 F.2d 227 (3d Cir. 1983).

5 District 27 Community School Board v. Board of Education of the City of New York, 502 N.Y.S.2d 325 (Sup. Ct., Queens Co. 1986).

${ }^{6}$ Id. at 332 .
} 
court relied on an earlier ruling that forbade the New York City Board of Education from excluding mentally retarded children who were carriers of the hepatitis B virus from public schools. ${ }^{7}$ If children with HBV, which was described as "far more contagious" than HIV, could not be excluded from schools, then certainly HIV-infected children could not be excluded. The exclusion of the children with HBV would make the schools "safer"; but any risk they posed was simply not sufficient to exclude them. Both of these courts were influenced by the fact that no effort was being made by the schools to identify either HIV- or $\mathrm{HBV}$-infected children. The schools were excluding infected children who were simply unfortunate enough to be identified in a haphazard way. Apparently the courts felt that if the risk presented by these children was not significant enough to expend effort and funds to identify them, the risk was also not significant enough to exclude them from school. This has obvious parallels to the exclusion of health care professionals when they happen to be identified, while denying the utility of mandatory testing.

These cases demonstrate that a fair antidiscrimination policy simply cannot be based on a "no risk" standard. Nor do exaggerated perceptions of risk justify exclusion. Instead, the law requires demonstration of a "significant risk" to exclude an otherwise qualified person from the workplace. In School Board of Nassau County v. Arline, the U.S. Supreme Court prohibited a school system from discharging a teacher who had a recurrence of tuberculosis she had contracted 20 years earlier. ${ }^{8}$ The Court found that having a contagious disease qualified a person as a "handicapped individual" under the federal Rehabilitation Act. She was therefore protected against discrimination unless she was not "otherwise qualified" to perform her job. The Court found:

A person who poses a significant risk of communicating an infectious disease to others in the workplace will not be otherwise qualified for his or her job if reasonable accommodation will not eliminate that risk. The Act would not require a school board to place a teacher with active, contagious tuberculosis in a classroom with elementary school children. ${ }^{9}$

7 N.Y. State Association for Retarded Children v. Carey, 466 F. Supp. 479 (E.D. N.Y.), aff'd, 612 F.2d 644 (2d Cir. 1979).

8480 U.S. 273 (1987).

${ }^{9}$ Id. at 1131, n.16 (emphasis added). 
To determine whether a person poses a significant risk, an "individualized inquiry" must be made in each case. The AMA offered standards for this inquiry that the Supreme Court adopted in Arline. The AMA said that a finding regarding the presence of a significant risk should be "based on reasonable medical judgments given the state of medical knowledge" about (1) how the disease is transmitted, (2) the duration of the risk, (3) the severity of the potential harm if the disease is transmitted, and (4) the probability of transmission.

The Americans with Disabilities Act (ADA) adopted this approach in its implementing regulations. One of the defenses available to an employer accused of discrimination under the ADA is that an otherwise protected person with a disability poses a "direct threat to the health or safety of the individual or others in the workplace." 10 The term "direct threat" is defined as "a significant risk of substantial harm to the health or safety of the individual or others that cannot be eliminated or reduced by reasonable accommodation." ${ }^{11}$ The regulations adopt the four Arline criteria, and add to that list "the imminence of the potential harm." The assessment of the presence of a direct threat of harm must be made on "the best available objective evidence." 12 The "interpretive guidance" appendix to this regulation states: "The risk can only be considered when it poses a significant risk, i.e., high probability, of substantial harm; a speculative or remote risk is insufficient." The party that wishes to exclude someone from the workplace bears the burden of proving the person is a direct threat.

The standard for assessing threat thus has two main parts: there must be (1) a high probability of (2) substantial harm. The arguments for excluding health care practitioners have focused solely on substantial harm, and have ignored the extremely low probability that this harm will occur. Any risk of death sounds too great when the probabilities are ignored. This is the same argument that was used to exclude wheelchair users from airplanes and hearing-aid users from driving school buses. However, one must assess the risk of death, not merely state its possibility. The risk of transmission of HIV from a physician or nurse to a patient is unknown because it has never happened. The risk of transmission

\footnotetext{
${ }^{10}$ Equal Employment Opportunity Commission. 1991. Equal Employment Opportunity for Individuals with Disabilities; Final Rule. 29 C.F.R. 1630.15 (b) (2) (July 26).
}

1129 C.F.R. 1630.2(r).

${ }^{12}$ Id. 
by a dentist is also unknown, even though one dentist has transmitted the virus to his patients. This is because the Acer case is unique and unexplained, especially given the fact that there have been no reported cases of HBV transmission from a dentist to a patient since 1987, and HBV transmission by the same route is at least 100 times more likely.

Estimates of risk of transmission of HIV are guesses about risk, not determinations of risk. They are based on what ifs: what if a surgeon cuts himself, and is infected with HIV, and the blood leaks out from his glove, and it is mingled with the patient's blood, and there is sufficient amount of virus actually to infect the patient. These what ifs lead to estimates of the risk of transmission ranging from $1 / 40,000$ to $1 / 400,000$ for surgeons, $1 / 260,000$ to $1 / 2.6$ million for dentists, to the chances of 1 infection per 28,000 to 500,000 hours of surgery by an infected surgeon, to the chance of 1 infection in 21 million to 300 million hours of surgery if the HIV status of the physician is unknown (Centers for Disease Control 1991d; Lowenfels and Wormser 1991). Former Surgeon General C. Everett Koop stated that the risk is so remote that it will probably never be measured (Hilts 1991). The Office of Technology Assessment (OTA) of the U.S. Congress analyzed the CDC's calculations of the risks of transmission and concluded that they are unreliable and likely to be overestimates (U.S. Congress 1991b). The OTA questioned each of the assumptions on which the calculations were based, noting that whether and how often they occur are unknown. We must remember that HIV infection has been apparently transmitted by only one dentist, and by no other health care professional in the ten years of the epidemic.

Whatever the exact probability of risk is, it is extremely low. Of all the factors that patients die from as a direct result of medical care, AIDS is at the bottom of a very long list. Because these other risks are virtually all higher than the risk of contracting AIDS from a health care practitioner and are socially acceptable risks, this risk does not qualify as significant risk in law. Therefore, the risk of HIV transmission from a practitioner also must be considered a socially acceptable risk.

\section{Misconstruing Risk}

The ability of policy makers and courts to assess rationally the low probability of the risk has been severely hampered by the real fear of death 
by AIDS. Two examples illustrate that some courts are simply not applying antidiscrimination law properly, either because of their own fear of AIDS, or because the experts did not distinguish between risk and harm.

The first case, Estate of William Bebringer v. The Medical Center at Princeton, ${ }^{13}$ involved the rights of an otolaryngologist and plastic surgeon who was diagnosed with AIDS in June 1987. Because the diagnosis was made at the hospital where he was on staff, fellow staff learned of his condition almost immediately. Within a few weeks, his surgical privileges were suspended. He died two years later, having never performed surgery again. The widespread knowledge of his disease resulting from hospital gossip caused both patients and employees to desert him. His practice declined, resulting in emotional suffering and financial loss. Several staff committees and the executive committee of the medical and dental staff, composed of physicians, concluded that the risk of transmission was so remote that there was no reason Dr. Behringer should not retain his surgical privileges, and additionally that the risk was so low that it need not be disclosed as part of informed consent. The lone dissenter was Dennis Doody, president of the medical center, who offered no scientific or medical basis for disagreeing.

Mr. Doody, having recruited no allies from the scientific community, called upon the hospital's legal counsel to support his feeling that a physician's HIV-positive status should be divulged in consent forms because of "legal and social considerations." At a meeting of the hospital's board of trustees, Mr. Doody "expressed concern about the hospital's reputation as well as potential litigation given public fear of AIDS." The trustees voted to require the use of a special consent form that would tell patients that a doctor was HIV positive. As the court noted (and as all parties agreed), "this was a de facto prohibition of surgery." Ultimately, based in part on the AMA's "no risk" policy statement (American Medical Association 1991), the trustees adopted a policy that health care practitioners "shall not perform procedures that pose any risk of HIV transmission to the patient." 14

The physician asserted that the trustees' policy violated the New Jersey Law Against Discrimination. The court recognized that New Jersey

${ }^{13}$ Estate of Behringer v. The Medical Center at Princeton, 249 N.J. Super. 597, 592 A.2d 1251 (Super. Ct. N.J. 1991).

${ }^{14}$ Id. (emphasis added). 
law requires an employer to prove a "reasonable probability of substantial harm" to others, and a "materially enhanced risk of serious injury to justify exclusion from the workplace." Having stated these legal standards, the court ignored them, saying instead that "there is little disagreement that a risk of transmission, however small, does exist." It also said, "It is the court's view that the risk of transmission is not the sole risk involved." This is remarkable, because the only risk involved is the risk of transmission. The court, however, apparently thought that the possibility of testing a patient for HIV, if a surgical accident occurred, should be considered a risk. However, the harm is dying of AIDS, not being voluntarily tested.

The court ultimately concluded that the medical center met its burden of showing that the physician presented a "reasonable probability of substantial harm," and therefore could bar him from performing surgery. There is not one word in the opinion that supports a finding of a reasonable probability of transmission. Instead, the court based its decision on the possibility of substantial harm. In short, the substantiality of the harm, death from AIDS, blinded the court to its obligation to objectively assess the risk of the harm.

More troubling is the Leckelt case in which two federal courts upheld the firing of a nurse because he refused to disclose the results of his HIV test. ${ }^{15}$ As a licensed practical nurse (LPN) Mr. Leckelt administered medications orally and by injection, changed dressings, performed catheterizations, administered enemas, and started intravenous tubes. He was occasionally assigned to the intensive care unit and to the emergency and surgical recovery rooms. Nurse Leckelt regularly wore gloves, washed his hands, and followed infection control procedures.

In April 1986 a patient was diagnosed as having AIDS at the hospital where Nurse Leckelt worked. This patient had been Nurse Leckelt's roommate for eight years, and Leckelt was "known to be a homosexual." 16 As a result, the hospital required him to take a test for HIV. Nurse Leckelt had already been tested, but had not received the results. The hospital would not schedule him for work until he provided the test results. Nurse Leckelt initially agreed, but later refused to provide the hospital with such test results and was fired for insubordination. Both

15 Leckelt v. Board of Commissioners of Hospital District 1, 909 F.2d 820 (5th Cir. 1990).

${ }^{16} \mathrm{Id}$. at 822 . 
the U.S. district court and the court of appeals accepted the hospital's pretext that Nurse Leckelt was not fired because he was suspected of having AIDS, but because he was "insubordinate" for not disclosing his HIV test results as ordered. The court of appeals did, however, address some of the antidiscrimination law issues. Correctly stating the four Arline criteria for determining the presence of a "significant risk," the court misapplied them. It acknowledged that the risk of transmission from a health care worker to a patient is "extremely low and can be further minimized through the use of universal precautions." ${ }^{17}$ However, the court observed that, because there is no cure for AIDS, the "potential harm" is extremely serious. The court felt that if the potential harm is death, the "extremely low" risk of death is irrelevant. If this is true, then eyeglass-wearing bus drivers are outside the protection of the law because if their glasses fall off they may go over a cliff and kill a busload of people. Even more remarkably, the court found that Nurse Leckelt generally complied with the hospital's universal precautions policies, and that the duties he performed did not fall within the definition of "invasive procedures," although "at least some of these duties provided potential opportunities for HIV transmission to patients." 18

In upholding Nurse Leckelt's firing, the court relied in part on CDC guidelines. For example, the court noted that if a health care worker has a parenteral or mucous-membrane exposure to blood or other bodily fluids, the CDC guidelines provided that the health care worker "should be evaluated chemically and serologically for evidence of HIV infection." 19 Further, CDC guidelines stated that a health care worker infected with HIV "should be" counseled about the risk of infection to himself or herself. The court said that the hospital could not comply with these recommendations without knowing Nurse Leckelt's HIV status. ${ }^{20}$ This, of course, is not true. Given the possibility of Leckelt's being HIV positive, in the absence of a test, the hospital could have treated him as if he were HIV positive. It could have counselled him. Because Nurse Leckelt did not perform invasive procedures, and used universal precautions when performing noninvasive procedures, he could not be deemed a significant risk to patients or other personnel,

\footnotetext{
${ }^{17}$ Id. at 829.

${ }^{18} \mathrm{Id}$.

${ }^{19}$ Id. at 828 .

${ }^{20}$ Id. at 830 .
} 
even if he were infected. Indeed, a draft of the CDC's proposed new recommendations (Centers for Disease Control 1991a) designate the procedures that Nurse Leckelt performed as noninvasive.

Nurse Leckelt was thus fired for not being tested for HIV, even though he could not be fired for having HIV infection. A federal court permitted the firing of an LPN, who did not perform invasive procedures, who used universal precautions, who could safely perform his duties, and who in no way could be said to be a significant risk to anyone, because his roommate of eight years had died of AIDS and Nurse Leckelt was known to be a homosexual. We think this remarkable outcome can only be attributed to a combination of AIDS phobia and homophobia, wrapped in the guise of a public health concern. The case illustrates how hospitals and courts misunderstand and misapply CDC recommendations to justify unlawful and unfair actions. Thus, in the absence of explicit guidelines, the CDC cannot assume that courts will use their recommendations properly.

These cases represent a growing trend among courts and policy makers to conflate perceived risk with actual risk, and an inability to distinguish a risk of harm from harm itself. Another recent example is the recommendation by the Federation of State Medical Boards (FSMB) to state licensing boards that they require all physicians who perform exposure-prone procedures to know their HIV and HBV status (Staver 1991). This mandatory testing proposal flows directly from the July 1991 CDC guidelines, even though the CDC did not recommend mandatory testing. If a doctor tests positive, the proposed policy says he should obtain the state licensing board's permission before continuing to perform such procedures. Physicians who treat HIV-infected physicians should report them to state licensing boards. The FSMB would not, however, require physicians to disclose their HIV status to patients.

In support of these recommendations Dr. James Winn, the FSMB's executive vice president, was quoted as saying, "The public perception is that something must be done about infected physicians even though scientifically there is only a remote chance of transmission. We wanted to restore public confidence without requiring the physician to disclose his HIV status to patients" (Staver 1991). We find disturbing Dr. Winn's belief that public confidence would be restored by creating a system that says doctors who perform "exposure-prone" procedures are so dangerous that they must be tested, approved by a state board if they are infected, and turned in by their colleagues, but that patients should 
not be told of their physician's HIV status. Even more remarkable is the statement by the FSMB president, psychiatrist Nancy Schneidman, referring to patients who are physicians. She said, "We're approaching this like many reportable diseases, such as syphilis and gonorrhea. . . . I also have to report patients who are sexual offenders. I don't see how this is any different" (Staver 1991). There are several differences, among them the fact that doctors with syphilis and gonorrhea are not reported to their licensing boards. Even more startling is Dr. Schneidman's analogy of doctors who are sex offenders and doctors who are infected with HIV. By definition, doctors who are sex offenders do not present a remote risk of harm in the future; they have already intentionally caused harm. This is but one more example of decreasing ability to distinguish harm from risk of harm.

The removal of HIV-infected health care practitioners from their workplaces has a major negative impact on these individuals' emotional well-being, finances, and role in society. It also prevents well-qualified, highly trained individuals from performing socially useful tasks (Rogers and Osborne 1991). Based on currently known facts, excluding them from practice is not good public health policy: it is unjustified discrimination. Thus, the risk of HIV transmission from a health care practitioner belongs in the category of risks that are accepted by society.

\section{Informed Consent}

Because Americans have a long history of permitting individuals to make their own decisions in medical care, it has seemed natural to propose that individual patients rather than public health agencies should decide whether an HIV-infected physician should continue to practice. However, proposals to require HIV-infected health care professionals to notify or inform patients of their status simply transfer the responsibility for reasoned risk assessment and public health policy to individual patients. Moreover, the doctrine of informed consent does not give rise to a general right to know personal details abcut one's physician, as the origins of the doctrine make clear.

The early informed consent cases were a response to physicians' paternalistic practice of withholding information about the risk of invasive procedures in order to spare patients the emotional discomforts accom- 
panying such knowledge. The problem was not that patients were receiving insufficient information, but rather that they were hearing no information regarding risks. This prevented patients from determining for themselves whether the possible benefits to be derived from a recommended procedure were outweighed by the possible risks.

The disclosure of a physician's HIV status presents a different set of issues. Unlike previous informed consent cases, the issue is not revealing risks of a procedure that are generally known to the medical community, but the mandatory disclosure of extremely private information about one person to another person. Once the information is disclosed it will not remain private, as past experience has taught us. Patients are under no obligation to keep their physician's private medical information confidential, and undoubtedly the community at large will learn of the physician's condition. Of course, this is the goal of disclosure. But it also means that the physician will lose his or her livelihood because of the fear engendered by AIDS. Even if hospitals and clinics are willing to continue to employ HIV-infected physicians, mandatory disclosure gives patients the de facto authority to exclude them from the workplace. Employers should not have the authority to exclude HIV-infected practitioners from working, absent the practitioner's presenting a "significant risk" or "direct threat" of serious harm, nor should employers be able to delegate this authority to patients.

Unlike early arguments disparaging informed consent, this argument is not at all paternalistic. The withholding of the HIV status of the patient's practitioner is not based on the premise that the patient may make a bad decision affecting him- or herself, but, rather, would make a decision adversely affecting another person. Therefore, information regarding an extraordinarily remote risk of harm may be withheld from a patient because of the certainty of harm that disclosure will cause the practitioner. This conclusion is not a departure from established law on informed consent. Nor does it diverge from ethical principles on informed consent. Furthermore, the extraordinarily remote risk of transmission itself would justify not disclosing it under the general informed consent rulings.

The fact that patients may want to know this personal information about their physician, dentist, or nurse, and may even act upon it, is not enough to conclude that there is an obligation to disclose such information. In a world in which infinitesimal risk is considered worthy of an affirmative obligation of disclosure, little private information is safe. 
Given the choice, patients might well wish to know if their male surgeon is a promiscuous homosexual or if their female surgeon engages in promiscuous heterosexual behavior. Regardless of what HIV tests show, patients might wish to avoid the increased risks, however small, these surgeons present over the confirmed monogamous surgeon. But we think few, if any, would argue that there is a duty to disclose one's sexual behavior just because patients are concerned. This interest might even be "rational" from patients' perspectives because they are seeking to reduce their risks, again, however small, of contracting HIV (see the article by Daniels in this issue). However, the avoidance of such remote risks by patients is not a sufficiently compelling reason to require the loss of privacy (and, ultimately, loss of livelihood) suffered by individuals forced to disclose intimate information about themselves.

In the New York school exclusion case, parents asked the court to order the school board to disclose the identity of the HIV-infected child if the court would not exclude the child from school. The concerned parents obviously wanted this information so that their child would not have to come in contact with the infected child. The parents' desire to protect their children was not "irrational." By avoiding and isolating the infected child the parents could avoid even the remotest of risks to their children. The court, however, would not allow this breach of privacy with its resulting stigmatization in order to soothe the parents' fear.

Until recently, courts have not required that personal information about physicians be disclosed to patients. In one case, the California Supreme Court said a physician-researcher should have disclosed his financial interest in a cell line he planned to develop from his patient's spleen. In the court's words:

A physician who treats a patient in whom he also has a research interest has potentially conflicting loyalties. . . . The possibility that an interest extraneous to the patient's health has affected the physician's judgment is something a reasonable patient would want to know in deciding whether to consent to a proposed course of treatment. It is material to the patient's decision and, thus, a prerequisite to informed consent. ${ }^{21}$

There seems to be no way to distinguish among disclosures about potential profit from a cell line, financial difficulties, kids in college, a mort-

${ }^{21}$ Moore v. Regents, University of California, 793 P.2d 479 (Cal. 1990). 
gage on a new boat, or a drop in the stock market that affects a doctor's net worth. Accordingly, the question to be addressed is, When is the conflict of interest serious enough to affect the physician's independent judgment of the patient's best interests? When it is, the physician should not be permitted to burden the patient with her conflict, but should have to disqualify herself from the case.

In a second case, a Louisiana court of appeals faulted a physician for failure to disclose his "alcohol abuse" to a patient. ${ }^{22}$ His patient lost control of his bladder and bowel following a laminectomy, although nothing in the case indicated that this resulted from the physician's alcohol abuse. The court noted that two years after this operation was performed, the physician's license was suspended on the grounds of "habitual or recurring drunkenness" and "medical incompetency." If it is true that this physician was a "habitual drunk" and "medically incompetent," then informing his patients of these facts should not be a defense to the injury these conditions caused, and the Louisiana court is wrong in concluding that such disclosure would be a defense. If a surgeon is not qualified, he should not practice. If the hospital in which he practices knows he is dangerous to patients, it has the responsibility to prohibit his practicing, and licensing boards should suspend or revoke the license of an unqualified practitioner. It should not be left to patients to make these decisions. We would be surprised if the AMA or CDC would instruct the "habitually drunk" surgeon either to discontinue practice or inform his patients that he suffers from alcoholism.

The law of negligence embodies the social policy decision that unqualified practitioners present socially impermissible risks. If unqualified, handicapped, alcoholic, or HIV-infected health care professionals present an impermissible risk to patients, they must be prevented from practicing to protect the public. Informed consent regarding their lack of skill or danger to patients is irrelevant. Similarly, we disqualify pilots with heart conditions from flying commercial passenger aircraft; we do not permit passengers to "consent" to the added danger of being piloted by someone who is at significant risk of suffering a heart attack during flight.

The doctrine of informed consent should not be distorted to enable hospitals or public health agencies to shift their burden of ensuring that practitioners are qualified to treat patients. Likewise, the doctrine of in-

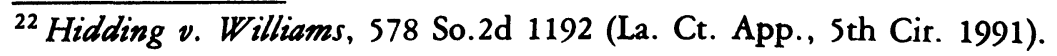


formed consent should not be used to destroy the privacy of an individual who is not just a health care practitioner, but also a person with rights.

This does not mean that patients may not ask practitioners about their HIV status, sexual preferences, and behavior or history of drug use or blood transfusion. However, practitioners need not answer. The freedom to ask does not imply any affirmative duty on the part of practitioners to disclose private information. Similarly, patients can ask physicians about their religious beliefs, racial ancestry, or national origins. Some patients might find the answers material and make decisions based on the answers. Again, the fact that patients would like to know this information does not mean that practitioners must disclose it. The practitioners' right is to keep private information private, if they so choose. If a patient is uncomfortable with a practitioner's refusal to answer, he or she is entitled to seek another practitioner, not to receive a nonvoluntary answer.

Current data regarding the risk of HIV transmission do not justify excluding infected practitioners from the workplace. Neither do they justify requiring practitioners to disclose their HIV status. Thus, the remote risk of HIV transmission cannot qualify as an optional risk that patients may choose to avoid. A patient's curiosity, however "rational," does not convert private information into a material risk that must be disclosed. The doctrine of informed consent should not be turned into a tool for discrimination. Moreover, proposals to require practitioners to disclose their HIV status so that patients can choose whether to be treated by them would undermine the rights of patients themselves by imposing on them the burden of determining whether a practitioner was qualified to practice. Patients who consented to be treated by an unqualified practitioner could be considered to have waived their rights to acceptable health care, and left without recourse if an injury resulted.

\section{Conclusion}

The transmission of HIV from David Acer to Kimberly Bergalis focused public concern on who transmitted HIV, not on how HIV was transmitted. What was feared was the person - a dentist, and by extension all physicians and other health care practitioners - not what a dentist did or did not do. Personalizing HIV infection diverted attention from 
the particular techniques and behaviors that can spread infection to particular groups of people.

Defining persons as the problem makes removing the persons the obvious solution. This reaction perpetuates the destructive stereotype that there are categories of people who are dangerous, previously limited to gay men and intravenous drug users, rather than behaviors that are dangerous, such as unprotected sex with multiple partners, needle sharing, and poor infection control techniques.

The policies of the CDC, the AMA, and others unintentionally legitimized this way of thinking. Although both groups have rightly called for the use of infection control techniques, they have also justified the removal of health care practitioners who represent only a theoretical risk to their patients. This has sent the message that health care practitioners constitute a deadly threat, and has drowned out the message of infection control.

Based on existing data, the exclusion of HIV-infected health care practitioners is unjustified as a matter of public policy and public health. Such a policy will not reduce the spread of HIV. It constitutes an empty gesture that responds to public fear in a symbolic but ineffective way. Consequently, it constitutes a distraction from the important and difficult tasks that are required to reduce the spread of HIV.

Exclusionary policies will have no positive effect on the AIDS epidemic, but they will have a serious negative impact on individual health care practitioners and on society as a whole. The proposed exclusionary policies demonstrate an inability to assess appropriately the nature of risks, and a willingness to stigmatize and harm sick people on the basis of fear alone. How we treat HIV-infected practitioners also will affect how we treat other disabled people who constitute a theoretical risk of harm. Exclusionary policies mean health care practitioners risk losing their livelihood if they learn of their infection or seek treatment. All people whose behavior puts them at risk for HIV infection should be encouraged to obtain diagnosis and treatment, and disincentives to such desirable behavior must be avoided as a matter of both public and personal health. As a result of the Bebringer, Leckelt, and similar cases, as well as the policies that we have described in this article, the only rational response of a health care practitioner who wishes to avoid stigmatization and loss of livelihood is to avoid diagnosis and treatment, or to keep such matters secret. 
Labeling HIV-infected health care professionals as too risky to practice their profession also sends them the wrong message. Health care practitioners are at significantly greater (although still low) risk of contracting HIV from patients than patients are of contracting HIV from them. Through a long and ongoing process, the health care professions have largely accepted the very low risk of contracting HIV infections and the obligation to treat HIV-infected patients (Gerbert et al. 1991). If we tell HIV-positive health care practitioners that they are too dangerous to treat patients, why should they not believe that HIV-positive patients are too dangerous to be treated? Policy makers cannot expect health care practitioners to continue to treat infected patients while at the same time arguing to exclude HIV-positive practitioners who pose a much lower risk of HIV transmission to patients than patients pose to them.

Instead of focusing on people with HIV infection, public health policy must turn its attention to the particular practices and procedures that facilitate HIV transmission. The CDC and AMA rightly recommend adherence to universal precautions. New technologies and techniques must be developed to prevent blood transfer. Enforcing policies for infection control is a more plausible and effective means of reducing the risk of HIV transmission than removing health care professionals from practices. It also has the advantage of preventing the transmission of other diseases.

The rules issued by the Occupational Safety and Health Administration (1991) on reducing exposure to bloodborne pathogens were entirely directed toward improving equipment and practices. This was not frontpage news. However, if we are to reduce further the small risk of transmission of bloodborne diseases, we must adopt and enforce OSHA's effective preventive measures, and not engage in the symbolic gesture that exclusionary policies represent. Good infection control policies have two great advantages over exclusionary policies: they can be effective if enforced, and they do not infringe on anyone's human rights.

Our position does not promise zero risk. It is possible that in the future a second health care practitioner will transmit HIV to a patient. If this occurs public health experts should do what they do best: find out how it happened and how it could have been prevented, and then educate the public, putting the event in proper perspective. If poor practice caused the problem, those responsible should be retrained or punished. The occurrence of harm does not change the analysis. The response 
should not automatically be to test all health care practitioners and stop their practices, any more than we stop anesthetizing patients in surgery when a patient dies from anesthesia.

The effort to improve the practice of health care practitioners should not be limited solely to those who present a risk of the particular harm of HIV infection; it should be part of a larger effort to ensure patient safety. The focus on HIV-infected health care professionals is suspect and discriminatory because it is not part of such an effort. Instead, it largely ignores the higher risks presented by myriad practices in the delivery of medical care.

The fact that HIV transmission from a health care practitioner to a patient is possible may make it "a risk" of health care, but does not make it a significant risk to public health or one that can be classified as socially impermissible. In the absence of any public health policy justification for discriminating against health care professionals, HIV transmission in the health care setting remains one of many acceptable risks that we must live with, and probably among the least dangerous ones. The burden of proof is on those who would exclude health care professionals with HIV infection from practicing their profession. That burden has not been met.

\section{References}

American College of Obstetricians and Gynecologists. 1991. Letter of September 27 from H.A. Kaminetzky, on behalf of the Executive Board, to the Centers for Disease Control. Washington.

American Medical Association. 1991. Statement on HIV-infected physicians, January 17. Chicago, Ill.

1988. Ethical Issues Involved in the Growing AIDS Crisis. Journal of the American Medical Association 259 (March 4):1360.

Annas, G.J., L.H. Glantz, and B.F. Katz. 1977. Informed Consent to Human Experimentation: The Subject's Dilemma. Cambridge, Mass.: Ballinger.

Armstrong, F.P., J.C. Miner, and W.H. Wolfe. 1987. Investigation of a Health Care Worker with Symptomatic Human Immunodeficiency Virus Infection: An Epidemologic Approach. Military Medicine 152:414-18.

Barnes, M., N.A. Rango, G.R. Burke, and L. Chiarello. 1990. The HIV-Infected Health Care Professional: Employment Policies and Public Health. Law, Medicine and Health Care 18:311-30. 
Barsky, A.J. 1988. Worried Sick: Our Troubled Quest for Wellness. Boston: Little, Brown.

Berke, R.L. 1991. AIDS Battle Reverting to "Us Against Them." New York Times (October 6):E1, 4.

Brennan, T.A., L.L. Leape, N.M. Laird et al. 1991. Incidence of Adverse Events and Negligence in Hospitalized Patients: Results of the Harvard Medical Practice Study I. New England Journal of Medicine 324:370-6.

Centers for Disease Control. 1985. Summary and Recommendations for Preventing Transmission of Infection with Human T-Lymphotropic Virus Type III/Lymphadenopathy-Associated Virus in the Workplace. Morbidity and Mortality Weekly Report 34:681-95.

1986. Recommendations for Preventing Transmission of Infection with Human T-Lymphotropic Virus Type III/LymphadenopathyAssociated Virus during Invasive Procedures. Morbidity and Mortality Weekly Report 35:221-3.

- 1987. Recommendations for Prevention of HIV Transmission in Health-care Settings. Morbidity and Mortality Weekly Report 36 (suppl. 2S):1S-19S.

- 1990. Possible Transmission of Human Immunodeficiency Virus to a Patient During an Invasive Dental Procedure. Morbidity and Morality Weekly Report 39 (July 27):489-93.

. 1991a. Revised Recommendations for Preventing Transmission of Human Immunodeficiency Virus and Hepatitis $\mathrm{B}$ Virus to $\mathrm{Pa}$ tients During Invasive Procedures, November 27, Atlanta, Ga. (Unpublished draft)

- 1991b. Recommendations for Preventing Transmission of Human Immunodeficiency Virus and Hepatitis B Virus to Patients During Exposure-Prone Invasive Procedures. Morbidity and Mortality Weekly Report 40 (no. RR-8, July 12):1-9.

. 1991c. HIV/AIDS Prevention Fact Book 1991 (HIV/ODD(HIV)/ 4-91/001). Atlanta, Ga.

- 1991d. Open meeting on the Risks of Transmission of Blood Borne Pathogens to Patients during Invasive Procedures, February 21-22 (HIV/ODD(HIV)3-91 \#002), Atlanta, Ga.

- 1991e. Update: Transmission of HIV Infection during an Invasive Dental Procedure-Florida. Morbidity and Mortality Weekly Report 40: (January 18):21-3.

- 1992. The Second 100,000 Cases of Acquired Immunodeficiency Syndrome - United States, June 1981-December 1991. Morbidity and Mortality Weekly Report 41:28-29.

Danila, R.N., K.L. MacDonald, F.S. Rhame et al. 1991. A Look-Back Investigation of Patients of an HIV-Infected Physician. New England Journal of Medicine 325:1406-11. 
Faden, R.R., and T.L. Beauchamp. 1986. A History and Theory of Informed Consent. New York: Oxford University Press.

Fischoff, B. 1981. Acceptable Risk. Cambridge, U.K.: Cambridge University Press.

Gerbert, B., B.T. Maguire, T. Bleeker et al. 1991. Primary Care Physicians and AIDS: Attitudinal and Structural Barriers to Care. Journal of the American Medical Association 266:2837-42.

Helms, J. 1991. The AIDS-Infected Physician-Are Criminal Penalties Necessary to Protect the Public Health? Yes, Protect Innocent Victims. American Bar Association Journal 77(October): 46.

Hilts, P.J. 1991. Mandatory AIDS Test for Doctors Would Be Useless Health Experts Say. New York Times (September 20):A22.

Holmes, S. 1991. For 2d Time Recently, an Airline Bars a Bush Aide in a Wheelchair. New York Times (October 6):24.

Kantrowitz, B. July 1, 1991. Doctors with AIDS: The Right to Know. Newsweek (July 1):48-57. (Cover story)

Leary, W.E. 1991. American Medical Association Backs Off on an AIDS Risk List. New York Times (December 15):38.

Lichtenstein, S., P. Slovic, B. Fischoff et al. 1978. Judged Frequency of Lethal Events. Journal of Experimental Psychology: Human Learning and Memory 4:551-78.

Lowenfels, A.B., and G. Wormser. 1991. Risk of Transmission of HIV from Surgeon to Patient. New England Journal of Medicine 325:888-9. (Letter)

Mishu, B., W. Schaffner, J.M. Horan et al. 1990. A Surgeon with AIDS: Lack of Evidence of Transmission to Patients. Journal of the American Medical Association 264:467-70.

New York State Department of Health. 1991. Policy Statement and Action Plan to Prevent Transmission of HIV through Medical and Dental Procedures, October 8. New York.

Occupational Safety and Health Administration. 1991. Occupational Exposure to Bloodborne Pathogens: Final Rule. 56 Federal Register (64004-64182; December 6; effective March 6, 1992).

Rescher, N. 1987. Risk and the Social Value of a Life. In Quantitative Risk Assessment, eds. J.M. Humber and R.F. Almeder, 225-37. Clifton, N.J.: Human Press.

Rogets, D.E., and J.E. Osborne. 1991. Another Approach to the AIDS Epidemic. New England Journal of Medicine 325:806-8.

Rosenthal, E. 1991a. Angry Doctors Condemn Plans to Test Them for AIDS. New York Times (August 20): C1,5.

- 1991b. Study Sees Moves on HIV Infection Backfiring. New York Times (September 10):C5. 
Scott, H.D. Sept, 1991. Public, Profession Need Reasoned Discussion of HIV Testing. American College of P.bysicians Observer 11(8):3.

Slovic, P. 1987. Perception of Risk. Science 236:280-5.

- 1991. Commentary. In Biomedical Politics, ed. K.E. Hanna, 302-7. Washington: National Academy Press.

Staver, S. 1991. Physicians to Report Physicians? American Medical News (November 11):31.

Tampa Tribune-Times. 1991. 213 Former Patients of Doctor Test Positive for Hepatitis Virus. (December 8):7.

Tolchin, M. 1991. Senate Adopts Tough Measures on Health Workers. New York Times (July 19): 1.

Tversky, A., and D. Kahneman. 1973. Availability: A Neuritic for Judging Frequency and Probability. Cognitive Psychology 5:207-32.

U.S. Congress. 1991a. H.R.2788: Kimberly Bergalis Patient and Health Provider Act of 1991. U.S. House of Representatives, 102d Congress, 1st Session. Introduced by Representative Dannemeyer, June 26.

Washington: Office of Technology Assessment.

- 1991c. S.185: AIDS Control Act of 1991, a Bill to Control the Spread of AIDS, and for Other Purposes. U.S. Senate, 102d Congress, 1st Session. Introduced by Senator Helms, January 14.

Wildavsky, A., and K. Dake. 1990. Theories of Risk Perception: Who Fears What and Why? Daedalus 119:41-60.

Williams, P. 1991. Debate over HIV Risk Heats Up. Medical World News (November):38-9.

Zeckhauser, R.J., and W.K. Viscusi. 1990. Risk within Reason. Science 248:559-64.

Address correspondence to: Leonard H. Glantz, J.D., Boston University School of Public Health, 80 East Concord Street, Boston, MA 02118-2394. 